\title{
EFFECTS OF HALOTHANE ON THE PHARMACOKINETICS OF LIDOCAINE IN DIGITALIS-TOXIC DOGS
}

\author{
James R. Boyce, Frank W. Cervenko, and Frederick J. Wright
}

\begin{abstract}
ANAESTHETISTS frequently deal with patients who are receiving digitalis. Since the therapeutic index of this drug is small (i.e. 3), and since these patients are often taking diuretics and are potentially hypokalaemic, digitalis induced ventricular arrhythmias are not uncommon during anaesthesia.

Lidocaine is used in the treatment of ventricular premature beats or ventricular tachycardia resulting from digitalis excess.' However, the dosage schedules for this drug are based on the pharmacokinetics in awake subjects. ${ }^{2}$ The present experiments were designed to study the effects of halothane on the pharmacokinetics of lidocaine in digitalis toxic dogs to determine if alteration in dosage schedules is required.
\end{abstract}

\section{MethoDs}

Eight healthy mongrel dogs weighing 10 to 23.5 kilograms were anaesthetized with pentobarbitone $30 \mathrm{mg} / \mathrm{kg}$ intravenously and intubated. The following physiological variables were monitored; end-tidal carbon dioxide using a Beckman infrared $\mathrm{CO}_{2}$ analyser; E.C.G. - standard lead II; oesophageal temperature; intra-arterial blood pressure. Periodic arterial blood gas and serum potassium analyses were made. When monitoring apparatus was established each dog was given ouabain by bolus injection intravenously (100$200 \mu \mathrm{gm}$ ) every ten minutes until ventricular arrhythmias appeared, indicating digitalis toxicity. Lidocaine was then given as a bolus injection intravenously in a dosage calculated to give a plasma concentration (Cp) of $6 \mu \mathrm{g} / \mathrm{ml}$ based on the formula: Dose $=\mathrm{Cp} \times \mathrm{Vd}(\mathrm{Vd}$, the estimated volume of distribution to be 60 per cent of the body weight). Arterial blood samples were taken at $1,2,3,4,5,6,8,10,15,30,60$ and 90 minutes after injection for plasma lidocaine analysis.

The dogs were then divided into two groups. Group 1, comprising four dogs served as controls. These animals were given a second dose of lidocaine (two-thirds of the initial dose) without concurrent halothane administration and blood

Address reprint requests to Dr. J.R. Boyce, Elba General Hospital, Elba, Alabama, U.S.A. samples were drawn as before for plasma lidocaine analysis. In Group 2, comprising four dogs, 1 per cent halothane in oxygen was administered from a Drager vaporizer for $30 \mathrm{~min}$ utes. When the end-tidal halothane concentration was 0.75 per cent or more, as measured by gas chromatography, a second bolus injection of lidocaine (two-thirds of the initial dose) was administered and blood samples were drawn for determination of plasma lidocaine levels.

\section{Plasma lidocaine analysis}

Plasma lidocaine was determined by a modification of the method of Benowitz and Rowland. ${ }^{3}$ Four $\mathrm{ml}$ of plasma were alkalinized with $0.01 \mathrm{ml}$ of $1 \mathrm{~N} \mathrm{NaOH}$. To each sample $12.5 \mu \mathrm{g}$ meperidine $\mathrm{HCl}$ was added as an internal standard. The lidocaine and meperidine were extracted with ether and evaporated to dryness. The samples were redissolved in $25 \mu$ l of chloroform and injected on the column in a HewlettPackard 420 gas-liquid chromatograph. The chromatograph specifications were: oven temperature $240^{\circ} \mathrm{C}$, injection port $260^{\circ} \mathrm{C}$, glass column $8^{\prime}$ SE-30 on chromosorb $W$. Elution times for the two major metabolites monoethylglycine $x y$ lidide (MEGX) and glycine $x y l i d i d e(G X)$ were established from known standards.

\section{Pharmacokinetic analysis}

The plasma lidocaine concentrations after each injection were plotted on semi-log paper with time in minutes as the $x$ axis (Figure 1). The bi-exponential regression was drawn as two straight lines through the log $y$ values corresponding to $x$ values of 1 to 6 minutes for the $\alpha$ phase and 15 to 90 minutes for the $\beta$ phase. The equation for the best fit line was obtained from an Olivetti calculator programmed for the method of least squares. The following pharmacokinetic data for each injection was derived from the biexponential regression curves: ${ }^{4}$

(1) $\alpha$ : the slope of the line through the $\log y$ values for times 1 to 6 minutes on the $x$ axis. Units are $\min ^{-1}$.

(2) $\beta$ : the slope of the line through the $\log y$ 


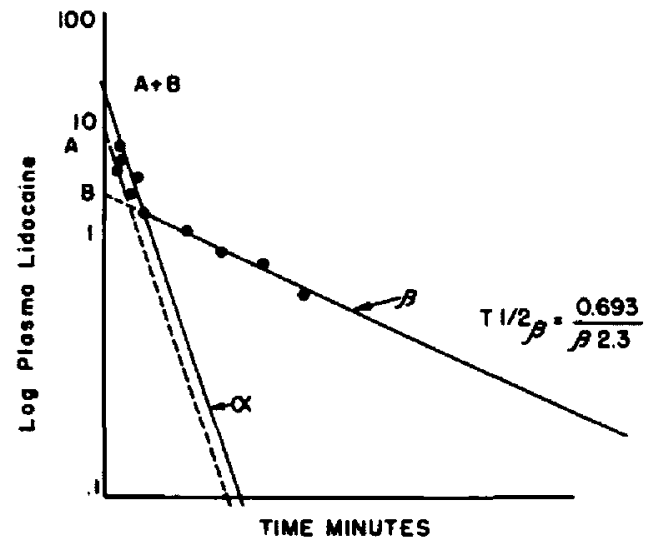

Figure I Bi-exponential curve of a drug after intervenous injection. $\alpha$ and $\beta$ phase represent distribution and elimination respectively.

values for times 15 to 90 minutes on the $\mathrm{x}$ axis. Units are min $^{-1}$.

(3) $T \frac{1}{2} \beta$ : the time required for the drug to reduce its concentration by 50 per cent. It is derived from the formula $T t \beta=(0.693 / 2.3 \beta)$.

(4) $\mathrm{Vd}$ : the volume of distribution. This is not an actual anatomical entity, but rather it is that volume which would be required to contain the drug if all the compartments in the body had identical concentrations as that found in the plasma. Its value is calculated from the equation

$$
V d=\frac{\text { Dose }}{\beta[(A / \alpha)+(B / \beta)]}
$$

(5) $\mathrm{Ke}$ : the elimination constant. This is the rate at which the drug is removed from the plasma by irreversible processes, i.e. metabolism. Its value is calculated by dividing the $A+$ $B$ intercept by the area under the curve:

$$
\mathrm{Ke}=\frac{A+B}{(A / \alpha)+(B / \beta)}
$$

The pharmacokinetic parameters were analysed for statistical significance using the Student's $t$-test.

\section{Results}

Effects of lidocaine on digitalis arrhythmia

Ouabain produced ventricular tachycardia in all dogs. In each case the bolus of lidocaine was effective in reverting the arrhythmia to sinus rhythm. No attempt was made to establish an effective plasma concentration of lidocaine because often the arrhythmia would not recur

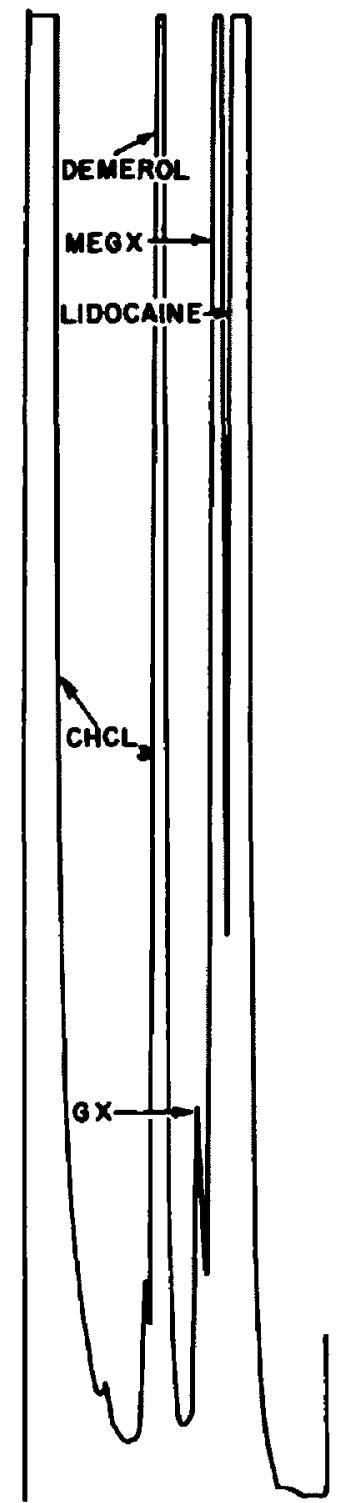

FIGURE 2 Chromatography separation of meperidine, glycine xylidide (GX), monoethylglycine xylidide (MEGX) and lidocaine.

throughout the experiment and, therefore, the plasma concentrations remained well above the effective therapeutic level.

\section{Identification of metabolites}

The assay outlined separated monoethylglycine xylidide (MEGX) and glycine xylidide (GX) from lidocaine (Figure 2). Only trace amounts of 
TABLE I

Pharmacokinetic Date For Group 1 (Controls) Mean \pm S.E.M.

\begin{tabular}{llcc}
\hline & & 1st Injection & 2nd Injection \\
\hline$\alpha$ & $\min ^{-1}$ & $-0.05625 \pm 0.01242$ & $-0.04299 \pm 0.00346$ \\
$\beta$ & $\min ^{-1}$ & $-0.01029 \pm 0.00392$ & $-0.00766 \pm 0.00225$ \\
$\mathrm{~T} \frac{1}{2} \beta$ & $\min _{\mathrm{V}}$ & $29.3 \pm 11.2$ & $39.3 \pm 11.6$ \\
$\mathrm{Le}$ & $\mathrm{L} / \mathrm{kg}$ & $1.33 \pm 0.54$ & $0.89 \pm 0.33$ \\
& $\min ^{-1}$ & $0.02193 \pm 0.01107$ & $0.01077 \pm 0.00153$ \\
\hline
\end{tabular}

TABLE II

Pharmacokinetic Data For Group 2 (Study Dogs) Mean \pm Ś.E.M.

\begin{tabular}{llcc}
\hline & & Before & During halothane \\
\hline$\alpha$ & $\min ^{-1}$ & $-0.03847 \pm 0.00597$ & $-0.04054 \pm 0.00314$ \\
$\beta^{*}$ & $\min ^{-1}$ & $-0.00882 \pm 0.00056$ & $-0.00238 \pm 0.00029$ \\
$\mathrm{~T} \frac{1}{2} \beta^{*}$ & $\min$ & $34.2 \pm 2.2$ & $126.6 \pm 15.4$ \\
$\mathrm{Vd}_{\mathrm{d}}$ & $\mathrm{L} / \mathrm{kg}$ & $0.81 \pm 0.18$ & $0.97 \pm 0.34$ \\
$\mathrm{Ke}$ & $\mathrm{min}^{-1}$ & $0.01208 \pm 0.00087$ & $0.00427 \pm 0.00067$ \\
\hline
\end{tabular}

*Statistically significant difference $(p<0.01)$.

MEGX were seen with lidocaine in the samples assayed.

\section{Effects of a second injection of lidocaine on its pharmacokinetics}

Table I lists the pharmacokinetic data for 2 separate injections of lidocaine in the same dog. There was no significant difference $(p>0.05$ ) between the first and second Lidocaine injections for $\alpha, \beta, \mathrm{T} \frac{1}{2} \beta, \mathrm{Vd}$ and $\mathrm{Ke}$.

\section{Effects of halothane on pharmacokinetics of lidocaine}

Table II lists the pharmacokinetic data for lidocaine boluses in dogs before and during halothane administration. There was no significant change ( $p>0.05$ ) in $\alpha$ and $V d$ before and during halothane anaesthesia. However, a significant difference exists between, $\beta, T \frac{1}{2} \beta$, and Ke after the administration of halothane ( $p<$ 0.01 ) (Figure 3 and Figure 4).

\section{Physiological variables}

Throughout the experiments the end-tidal $\mathrm{PCO}_{2}$, arterial blood gas and serum potassium analyses and oesophageal temperature were within normal limits. The mean arterial blood pressure did decline significantly $(p<0.05)$ from $22.6 \pm 1.33 \mathrm{SE} \mathrm{kPa}(170 \pm 10 \mathrm{SE} \mathrm{mm} \mathrm{Hg})$ to 18.6 $\pm 1.68 \mathrm{SE} \mathrm{kPa}(140 \pm 12.6 \mathrm{SE} \mathrm{mm} \mathrm{Hg})$ with the introduction of halothane.

\section{Discussion}

These experiments demonstrated that halothane has a significant influence on the pharmacokinetics of lidocaine.

When a drug is administered intravenously the decline in the plasma concentrations can be divided into two distinct phases an $\alpha$ and a $\beta$ phase. The $\alpha$ phase is a fall in plasma concentration due to redistribution of the drug from the plasma and extracellular fluid of the vessel rich group of organs (the so-called central compartment) to the less perfused tissues such as the muscles and fat (peripheral compartment) (Figure 5). This phase follows first order kinetics and therefore can be represented as a straight line when the plasma concentrations are plotted against time on semilog paper. The slope of the line, $\alpha \times 2.3$ represents the fraction of drug removed from the plasma per unit time. The experiments show that halothane does not significantly affect this "distribution" " phase (Figure 3).

In addition to redistribution, lidocaine is removed from the plasma by elimination processes which are mainly metabolic. When the peripheral compartment approaches saturation, then the plasma concentration falls by first order kinetics and the slope of the line representing this process is $\beta$, which again when multiplied by 2.3 gives the elimination constant for $\beta$ phase. Factors affecting $\beta$ are the metabolic elimination processes and the balance of the amount of drug exchanged between the central and peripheral compart- 


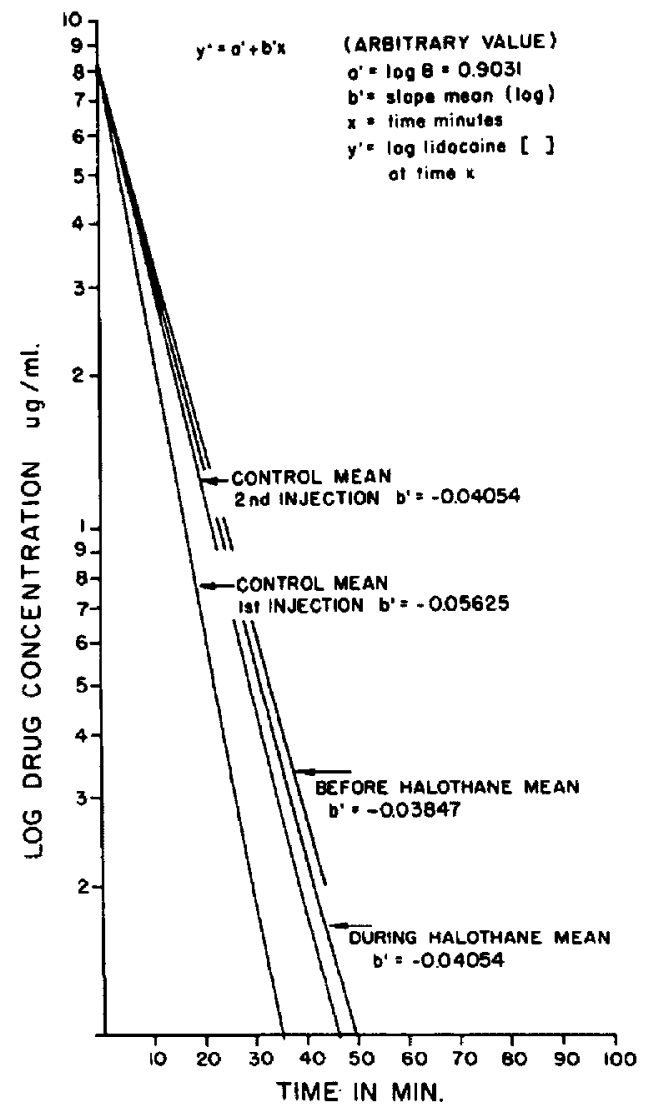

Figure 3 Comparison of $\alpha$ (distribution) phase of lidocaine following first and second injections in control dogs and following lidocaine injections before and during halothane.

ments. These experiments show that halothane has a profound effect on $\beta$ so that a significantly smaller fraction of drug is removed from the plasma per unit time when halothane is administered (Figure 4).

Since halothane did not significantly affect $\alpha$, then the only two other possibilities are its effect on the rate with which drug leaves the peripheral compartment and re-enters the central compartment (Figure 5), or its effect on metabolism as the main elimination process, $\mathrm{Ke}$. As seen from Table II, there is a significant difference in the mean Ke before and during halothane. Halothane could slow the rate of metabolism of lidocaine by two possible mechanisms. First it could interfere with the enzyme system responsible for oxidative de-ethylation. The biodegradation of both halothane and lidocaine involves NADPH dependent cy tochrome $\mathrm{P}-450$ and perhaps competitive inhib-

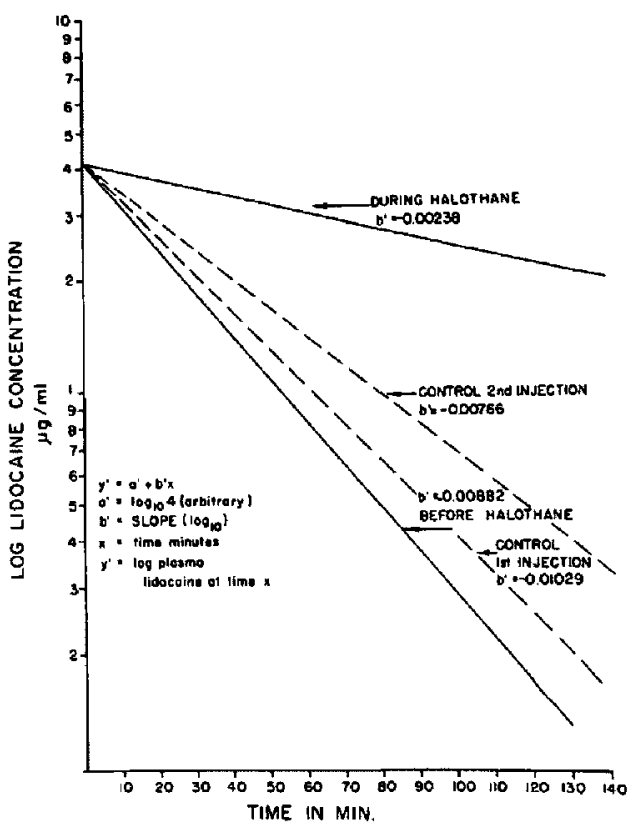

Figure 4 Comparison of $\beta$ phase (elimination) of lidocaine following first and second injections in control dogs and following lidocaine injections before and during halothane.

ition occurs. Sawyer, et al. ${ }^{5}$ have shown that varying halothane concentrations affect its own metabolism. In normal swine $1 \mathrm{MAC}$ halothane has an inhibitory effect on its own metabolism such that by comparing hepatic artery-portal vein and hepatic vein levels of halothane, no metabolism occurs. The mechanism of this inhibitory effect remains to be clarified but a similar mechanism could be the cause of decreased lidocaine metabolism in the presence of halothane. Another possible mechanism is that halothane

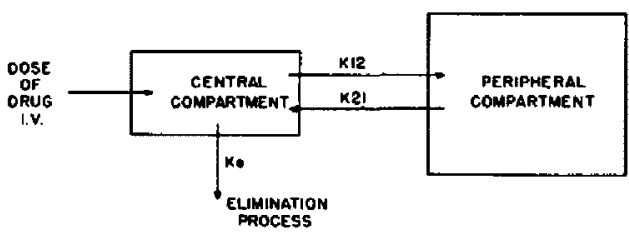

Figure 5 Two compartment model for disposition of a drug injected as a bolus intravenously. Central compartment = plasma and extracellular fluid of vessel rich tissue. Peripheral compartment $=$ tissue less welt perfused. $K_{12}=$ rate constant for transfer of a drug from central to peripheral compartment. $K_{21}=$ rate constant for transfer of a drug from peripheral to central compartment. Ke = rate constant of irreversible elimination, i.e. metabolism. 
decreases hepatic perfusion and, consequently, less drug is transported to the site of biodegradation in the hepatocytes. That halothane does decrease liver blood flow has been shown by Epstein, et al. ${ }^{6}$ Burney and DiFazio 7 and DiFazio and Brown ${ }^{8}$ reported a lidocaine elimination constant in dogs of $0.0122 \pm 0.0013 \mathrm{~min}^{-1}$ during nitrous oxide-curare anaesthesia, which is similar to our value of $0.01208 \pm 0.00087 \mathrm{~min}^{-1}$ during pentobarbitone anaesthesia. Their reported $\mathrm{Ke}$ for lidocaine during halothane anaesthesia (inspired concentration 0.25 to 0.5 per cent) was $0.0081 \pm$ $0.003 \mathrm{~min}^{-1}$ compared to our value of $0.00427 \pm$ $0.00067 \mathrm{~min}^{-1}$ (inspired concentration 1 per cent, end-tidal 0.75 per cent). These results suggest that the depression of lidocaine elimination during halothane is related to depth of anaesthesia.

The $T t \beta$ is usually referred to as the half life of a drug and halothane significantly prolonged this value for lidocaine from $34.2 \pm 2.2 \mathrm{~min}$ to $126.6 \pm$ $15.4 \mathrm{~min}$. The data indicate that it would take over two hours as opposed to 35 minutes for the plasma lidocaine concentration to decrease from 4 to $2 \mu \mathrm{g} / \mathrm{ml}$. The clinical importance of this effect of halothane pertains to lidocaine dosage schedules. Since halothane did not significantly change the volume of distribution, Vd, then the initial loading dose would not have to be altered. However, the altered $\beta$ would mean that the rate of infusion would have to be decreased to prevent toxic levels being attained. For example, in the control dogs with a mean weight of $18.25 \mathrm{~kg}$ if, after a loading dose, an infusion of lidocaine was given to maintain a plasma concentration of 4 $\mu \mathrm{g} / \mathrm{ml}$, then the infusion rate $\mathrm{R}$, would be: $\mathrm{R}=\mathrm{Cp}$ $\times \beta \times V d=4 \times 0.00882 \times 0.81 \times 18.25=0.52$ $\mathrm{mg} / \mathrm{min}$. During halothane anaesthesia, the same rate of infusion would produce a higher plateau concentration of lidocaine:

$$
\begin{aligned}
\mathrm{Cp}=\frac{\mathrm{R}}{\beta \times \mathrm{Vd}}=\frac{0.52}{0.00238 \times(0.81 \times 18.25)} & \\
& =14.8 \mu \mathrm{g} / \mathrm{ml}
\end{aligned}
$$

This new plasma concentration is clearly in the toxic range. The new rate of lidocaine infusion required to maintain a plasma concentration of 4 $\mu \mathrm{g} / \mathrm{ml}$ in the dogs anaesthetized with halothane would be:

$\mathrm{R}=4 \times 0.00238 \times(0.18 \times 18.25)=0.14 \mathrm{mg} / \mathrm{min}$.

Hence, during halothane anaesthesia in dogs, almost a four-fold reduction in infusion rate would be required. There are no data available to indicate how long this state of impaired lidocaine metabolism extends past the cessation of halothane anaesthesia.

Hurnan studies of a similar nature will be necessary before specific recommendations can be made. However, on the basis of these animal studies it would appear that halothane anaesthesia could impair the metabolism of lidocaine enough to suggest a decrease in the recommended infusion rates, even though the recommended loading dosages need not be changed.

\section{SUMMARY}

Following the production of digitalis toxicity in dogs as manifested by ventricular tachycardia, the pharmacokinetics of lidocaine treatment of the arrhythmia were determined during pentobarbitone anaesthesia and pentobarbitone-halothane anaesthesia. The elimination rate constants, $\beta$ and $\mathrm{Ke}$, and the biological half life $\mathrm{T} / \mathrm{t} \beta$ were statistically significantly increased during halothane anaesthesia. The volume of distribution was unchanged. The results indicate that the therapeutic loading dose of lidocaine need not be al tered during halothane anaesthesia but if a constant infusion is used, the rate of infusion would have to be decreased four fold to avoid toxic plasma levels of lidocaine.

\section{RÉSUMÉ}

Après avoir provoqué chez le chien de la tachycardie ventriculaire par intoxication digitalique, les auteurs ont étudié la pharmacocynétique de la lidocaine lors du traitement de l'arythmie sous anesthésie au pentobarbital seul et à l'halothane associé au pentobarbital. L'analyse statistique a mis en évidence une augmentation significative de la vitesse d'excrétion (constantes $\beta$ et $\mathrm{Ke}$ ) et de la demi-vie biologique $\left(\mathrm{T}_{2} \beta\right)$ pendant l'anesthésie à l'halothane. Le volume de distribution n'a pas changé. D'après ces résultats, il ne semble pas nécessaire d'augmenter la dose d'attaque de lidocaine sous anesthésie à l'halothane. Toutefois, lors d'administration continue, la perfusion devrait être ramenée au quart de sa vitesse habituelle pour éviter une augmentation de la concentration plasmatique jusqu'à des niveaux toxiques.

\section{REFERENCES}

1. Bigger, J.T. \& Heissenduttal, R.H. Use of procaine amide and lidocaine in the treatment of cardiac arrhythmias. Progress in Cardiovascular Disease, Vol XI 6:515 (1969) 
2. Thomson, P.D., Melmon, K.L., Richardón, J.A., Cohn, K., Steingrunn, W., Cudihee, R., \& RowlAND, $M$. Lidocaine pharmacokinetics in advanced heart failure, liver disease, and renal failure in humans. Ann. Int. Med. 78: 499 (1973).

3. Benowitz, N. \& Rowland, M. Determination of lidocaine in blood and tissues. Anesthesiology 39: 639 (1973).

4. Greenblatt, D.J. \& Koch-Weser, J. Clinical pharmacokinetics. N.E.J.M. Part I 293(14): 702; N.E.J. M. Part 2 293(19): 964 (1975).

5. Sawyer, D.C.. Eger, E.I.11, Bahlman, S.H., Culleen, B.F., \& IMPELMAN, D. Concentration dependence of hepatic halothane metabolism. Anesthe siology 34:230 (1971).

6. Epstein, R.M., Deutsch, S., Cooperman, L.H., Clement, A.J., \& PRICE, H.L.Splanchnic circulation during halothane anesthesia and hypercapnia in normal man. Anesthesiology 27:654 (1966).

7. BURNeY, R.G. \& DiFAZIo, C.A. Hepatic clearance of lidocaine during $\mathrm{N}_{2} \mathrm{O}$ anesthesia in dogs. Ane sth. and Analg. 55: 322 (1976).

8. DiFAz1O, C.A.\& BRown, R.E. Lidocaine metabolism in normal and phenobarbital-pretreated dogs. Ane sthe siology 36: 238 (1972). 